\title{
PETUAH PENDIDIKAN KEWARGANEGARAAN DALAM KONTESTASI POLITIK
}

\author{
T Heru Nurgiansah \\ Universitas PGRI Yogyakarta \\ Jl. PGRI I Sonosewu No. 117 Bantul, Yogyakarta \\ Email: nurgiansah@upy.ac.id
}

\begin{abstract}
ABSTRAK
Ajang pemilihan umum menjadi momen yang tepat dalam mengimplementasikan demokrasi di Negara Indonesia. Para kontestan saling beradu menjadi pemenang di hati masyarakat. Disinilah pentingnya Pendidikan Kewarganegaraan baik bagi pemilih maupun bagi figur yang mencalonkan diri. Tujuan Penelitian ini adalah untuk mengetahui bangaimana konsep Pendidikan Kewarganegaraan dalam Kontestasi Politik. Metode penelitian ini menggunakan metode Kualitatif. Teknik pengumpulan data dalam penelitian ini menggunakan observasi, wawancara dan studi literasi. Hasil penelitian ini mengatakan bahwa dalam kontestasi politik diperlukan sikap demokratis, bertanggung jawab, dan partisipatif, yang semuanya ada dalam konsep Pendidikan Kewarganegaraan.
\end{abstract}

Kata Kunci: Pendidikan Kewarganegaraan, Kontestasi Politik.

\begin{abstract}
The election event became the right moment in implementing democracy in the country of Indonesia. Contestants are contenders with the winners in the hearts of society. Here is the importance of citizenship education both for voters and for the figure who is running. The purpose of this research is to know the concept of citizenship education in political contestation. This method of research uses qualitative methods. The data collection techniques in these studies use observations, interviews, and literacy studies. The results of this study say that political contestation required a democratic, responsible, and participatory attitude, which all exist in the concept of citizenship education.
\end{abstract}

Key Word: Civic Education, Political Contestation.

\section{PENDAHULUAN}

Berbicara mengenai Pendidikan Kewarganegaraan tidak akan pernah menemukan ujungnya karena mata pelajaran ini sangat luas cakupannya. Pendidikan Kewarganegaraan bisa diasumsikan sebagai pendidikan nilai, pendidikan moral, pendidikan hukum, bahkan pendidikan politik. Saking banyaknya konsep tersebut menjadikan Pendidikan Kewarganegaraan menjadi mata pelajaran wajib (Bunyamin, 2008). Wajib di sini berarti mata pelajaran ini ada di berbagai jenjang pendidikan formal mulai dari pendidikan dasar, pendidikan menengah, sampai ke perguruan tinggi dan tidak hanya berlaku secara teritorial saja akan tetapi bersifat nasional.

Sebagai pendidikan nilai dan moral, Pendidikan Kewarganegaraan tidak hanya mengedepankan aspek pengetahuannya saja akan tetapi aspek sikap dan keterampilan pun tidak luput dari fokus indikatornya karena Pendidikan Kewarganegaraan bertujuan untuk 
membangun karakter (Character Building) bangsa Indonesia (Nasution, 2016). Pendidikan Kewarganegaraan sebagai pendidikan nilai dan moral berarti harus dipraktekan, tidak hanya mencakup teorinya saja agar dapat menumbuhkan karakter yang kuat. Pendidikan Karakter adalah untuk menumbuhkan nilai-nilai karakter (Nurgiansah, 2019). Karakter bangsa Indonesia yang dimaksud adalah bangsa yang cerdas, kreatif, kritis, sesuai dengan amanat Undang-Undang. Character education is a good solution to be implemented to form a strong character of the younger generation, yang berarti pendidikan karakter merupakan solusi yang tepat bagi generasi muda (Nurgiansah et al., 2020).

Selain itu Pendidikan Kewarganegaraan merupakan bagian penting dari pembentukan warga negara yang baik (Hemafitria, 2015). Warga negara yang baik adalah warga negara yang demokratis, patuh hukum, dan cinta terhadap tanah airnya. Pendidikan Kewarganegaraan juga memiliki peran penting dalam mempengaruhi atau memberikan pemahaman terhadap politik (Rahman, 2018). Politik dan Pendidikan Kewarganegaraan merupakan dua hal yang tidak dapat dipisahkan karena keduanya memiliki tujuan yang sama yakni menjadikan warga negara yang berpartisipasi.

Pendidikan politik juga bertujuan untuk membentuk warga negara yang baik (Hermawan, 2020). Dalam bidang politik konsep dasarnya adalah memilih dan dipilih. Artinya warga negara yang baik dalam persfektif politik yakni warga negara yang mau berpartisipasi dalam dunia politik, bisa dengan cara melek politik yang berkembang dewasa ini atau terjun langsung dalam politik praktis seperti mengikuti pencalonan dan pemilihan Kepala Daerah.

Pemilihan Kepala Daerah dijadikan sebagai arena pertarungan untuk mendapatkan sebuah pengakuan (Budi Ali, 2012). Pengakuan dari masyarakat bahwa figur atau sosok tersebut layak untuk menang dan menempati posisi strategis dalam perpolitikan. Namun dalam pelaksanaannya seringkali terjadi pelanggaran-pelanggaran bahkan dimulai sejak seseorang dinyatakan sebagai bakal calon. Praktik menghalalkan segala cara dengan menerobos aturan yang telah disepakati membuat masyarakat pemilih menjadi antipati terhadap calon tersebut yang berimplikasi terhadap tingginya angga golput dan rendahnya partisipasi masyarakat dalam menyalurkan suaranya.

Tingginya angka golput pada setiap penyelenggaraan pemilihan umum patut diwaspadai (Helen NM, 2019). Jika hal ini dibiarkan terus menerus maka akan terjadi deparpolisasi, yakni semakin menipisnya pengakuan masyarakat terhadap partai politik dan tokoh politik sehingga peran dari partai politik tidak lagi terlihat di mata masyarakat. Partai-partai di Indonesia memobilisasi isu-isu yang menjadi kepentingan anggota 
masyarakat (Muksin, 2018). Jika isu-isu yang berkembang di masyarakat ini difasilitasi oleh tokoh politik mauoun partai politik, maka kepercayaan masyarakat terhadap perpolitikan di Indonesia semakin meningkat seiring dengan bertambahnya partisipasi masyarakat.

Partisipasi politik adalah kegiatan-kegiatan sukarela dari warga masyarakat (Sutisna, 2017b). Sukarela berarti tanpa adanya paksaan, intimidasi, maupun embel-embel lainnya yang membuat masyarakat tergerak. Dengan semakin banyaknya masyarakat yang dengan sukarela berpartisipasi dalam politik, maka dipastikan iklim politik di daerah tersebut semakin baik. Namun jika kesukarelaan masyarakat ini rendah berarti iklim perpolitikan di wilayah tersebut belum optimal. Untuk mengoptimalkan kegiatan politik di suatu wilayah tertentu diperlukan masyarakat yang bisa mengkonsep dirinya sendiri. Konsep diri ini sangat penting sebagai pertimbangan apakah seseorang bisa dikatakan aktif berpartisipasi atau menjadi seseorang yang apatis. identitas sosial seseorang ikut membentuk konsep diri (Budiman \& Setyahadi, 2019). Konsep diri inilah yang akan menghasilkan kontestasi politik yang bersih dan akuntabel. kontestasi politik yang damai diperlukan dalam rangka membangun kualitas sistem politik demokrasinya agar tercipta pemerintahan yang baik (Ngurah et al., 2019).

\section{METODE PENELITIAN}

Penelitian ini menggunakan metode kualitatif karena dengan metode ini permasalahan yang terjadi di lapangan bisa terurai dan teranalisis dengan lebih mendalam. Metode penelitian kualitatif sering disebut dengan metode penelitian naturalistik karena sifatnya yang natural, apa adanya sesuai dengan temuan di lapangan (Nurgiansah \& Widyastuti, 2020).

Teknik pengumpulan data menggunakan catatan observasi langsung, wawancara dengan narasumber yang ahli di bidangnya, dokumentasi sesuai dengan potret di lapangan dan studi kepustakaan. Observasi berarti pengamatan secara langsung di lokasi penelitian dalam hal ini wilayah Daerah Istimewa Yogyakarta yang meliputi Kota Yogyakarta, Kabupaten Gunung Kidul, Kabupaten Kulonprogo, Kabupaten Sleman, dan Kabupaten Bantul. Wawancara dilaksanakan secara terstruktur agar penelitian lebih terfokus pada petuah Pendidikan Kewarganegaraan yaitu untuk membentuk warga negara yang baik. The interview is a data collection with a path of question and answer that is conducted systematically and based on the purpose of investigation (Nurgiansah, 2020). Yang berarti Wawancara tersebut merupakan pendataan dengan jalur tanya jawab yang dilakukan secara 
sistematis dan berdasarkan tujuan penyelidikan. Wawancara sistematis dilaksanakan secara berurutan mulai dari pertanyaan yang mendasar sampai ke pertanyaan yang semakin kompleks. Selanjutnya adalah dokumentasi digunakan agar data yang diambil tidak hilang atau berubah dan dapat dijadikan sebagai arsip penelitian. Kemudian literatur digunakan sebagai penunjang data dengan bersumber pada artikel jurnal yang relavan dengan penelitian. Literatur adalah serangkaian kegiatan yang berkenaan dengan metode pengumpulan data pustaka, membaca dan mencatat, serta mengelolah bahan penelitian (Sutrisno et al., 2018).

\section{HASIL DAN PEMBAHASAN}

Petuah Pendidikan Kewarganegaraan bisa diasumsikan sebagai wejangan, tujuan, keinginan, ataupun harapan. Warga negara yang baik inilah yang menjadi petuah dari Pendidikan Kewarganegaraan. Pendidikan Kewarganegaraan adalah segala sesuatu yang berkaitan dengan warga negara. Pendidikan Kewarganegaraan adalah pendidikan demokrasi yang bertujuan untuk mempersiapkan warga masyarakat berpikir kritis dan bertindak demokratis (Sagala, 2019). Berpikir kritis berarti ikut berkomentar mengenai hal apapun yang sedang hangat terjadi di lingkungan sekitar. Dengan berfikir kritis maka warga negara bisa mengetahui peran dan kedudukannya dalam hierartki pemerintahan. Berpikir kritis bisa memunculkan literasi yang akan berdampak pada pergerakan masyarakat dalam berpolitik praktis. Literasi media dapat meningkatkan partisipasi politik secara lebih signifikan (Bashori, 2018). Peningkatan partisipasi politik dapat meningkatkan indeks demokrasi suatu negara. Jika partisipasi politik masyarakatnya rendah maka akan mengakibatkan sikap acuh tak acuh dari masyarakat sehingga tidak peduli dengan adanya pelaksanaan pemilihan kepala daerah dan menutup mata serta telinga terhadap keberadaan partai politik. Absennya literasi politik pada segmen pemilih pemula secara hipotetis juga dapat menyuburkan apatisme politik (Sutisna, 2017a).

Pada era sekarang, konsep partisipasi tidakk hanya terjun langsung di lapangan. Ada media yang dapat memfasilitasi partisipasi politik masyarakat. Keberadaan media massa adalah untuk menginformasikan dan mengkampanyekan suatu tujuan (Zulhazmi, 2019). Terjadi pergeseran konsep media masa. Dahulu media masa hanya berupa media cetak berupa koran, jurnal, dan buku. Namun sekarang media masa bersifat elektronik atau modern seperti media sosial, gadget, dan alat teknologi lainnya.

Petuah Pendidikan Kewarganegaraan menekankan pada kita selaku masyarakat baik yang berkecimpung di dunia politik maupun para akademisi tentang eksistensi atau 
keberadaan dari sebuah partai politik. Melalui partai politik masyarakat dapat menyalurkan kehendak dan aspirasinya (Sarbaini, 2014). Aspirasi masyarakat harus didengar oleh para tokoh politik sehingga masyarakat merasakan bahwa keberadaannya dibutuhkan tidak pada saat menjelang pemilihan umum saja.

Aspirasi masyarakat juga merupakan alat kontrol paling efektif dalam perpolitikan. Seperti kita ketahui bahwa dalam negara demokrasi seperti Indonesia ini, kedudukan tertinggi ada di tangan rakyat karena jabatan rakyat adalah langgeng sepanjang jaman berbeda dengan jabatan politik yang hanya berlangsung 5 sampai 10 tahun saja. Selain itu aspirasi masyarakat perlu diakomodir agar kejadian 1998 tidak terulang kembali.

Lengsernya presiden Soeharto tahun 1998 mencoreng status warga negara yang baik karena saat itu terjadi perusakan dan penjarahan karena tidak difasilitasinya aspirasi masyarakat yang menginginkan perubahan. Sejak saat itu pemilihan umum tidak lagi dilangsungkan di gedung DPR / MPR. Maka tahun 2004 merupakan kebangkitan dari petuah Pendidikan Kewarganegaraan karena masyarakat bisa memilih tokoh politiknya secara langsung sesuai dengan selera dan keinginan mereka.

Pemilihan umum merupakan suatu hal yang sangat penting dalam demokrasi (Rahman, 2017). Tanpa adanya pemilihan langsung maka negara demokratis ini akan berubah, bergeser menjadi negara diktator atau kerajaan. Dalam sistem kerajaan pemilihan pejabat sesuai dengan garis keturunan raja. Bahkan perintah atau titah raja bisa langsung menjadi sebuah undang-undang yang wajib dijalankan oleh masyarakat. Begitu pula dengan negara atau pemimpin yang diktator, maka tidak ada lagi kontrol dari masyarakat yang akan menjadi penilai dalam sebuah kebijakan yang dihasilkan. Oleh karena itu, petuah Pendidikan Kewarganegaraan sangat menekankan adanya pemilihan umum secara langsung. Pilkada secara langsung merupakan progres yang sangat baik dalam proses demokrasi sejak era reformasi (Fatwa, 2016).

Sebelum reformasi, pemilihan umum secara langsung mustahil untuk dilaksanakan. Bahkan keberadaan dari partai politik pun dikebiri dengan hanya berjumlah 3 partai politik saja yakni partai Golongan Karya (Golkar), Partai Demokrasi Indonesia Perjuangan (PDIP), dan Partai Persatuan Pembangunan (PPP). Namun pasca tegaknya reformasi jumlah partai politik Indonesia menjadi membengkak sampai 40 lebih. Dan yang paling fenomenal adalah amandemen terhadap Undang-Undang Dasar 1945 sebanyak 4 kali dimulai dari tahun 1999 tentang pembatasan kekuasaan menjadi maksimal 10 tahun, 2000 tentang pembentukan daerah otonom, 2001 tentang pemilihan umum secara langsung, dan 2002 tentang penghapusan Dewan Pertimbangan Agung. 
Amandemen pertama tahun 1999 merupakan hasil dari 32 tahun lamanya kekuasaan presiden. Dengan adanya pembatasan kekuasaan maka hak-hak politik orang lain akan lebih terakomodir dan bisa mencalonkan diri menjadi pejabat berikutnya.

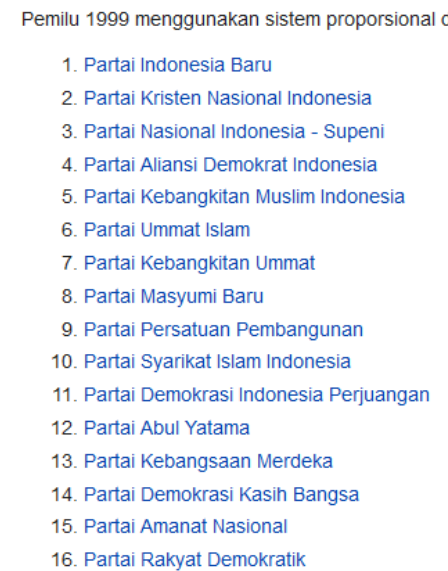

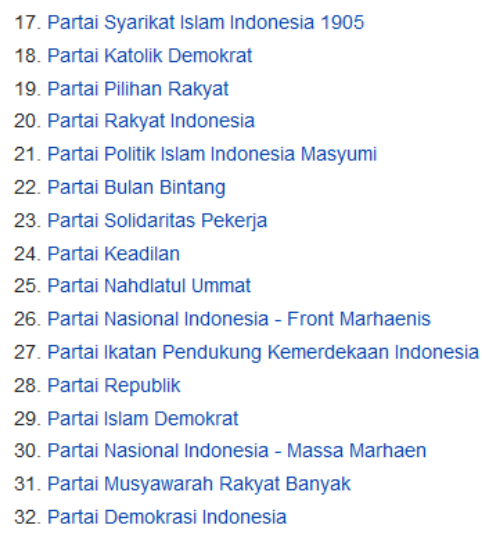

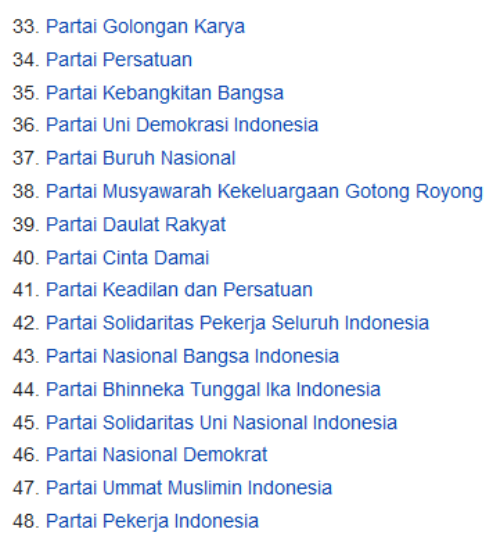

\section{Gambar 1. Daftar Partai Politik Di Awal Reformasi Tahun 1999}

Dalam pemilihan umum secara langsung, maka rakyat dapat mengendalikan dan mengontrol keputusan pemerintahan (Nadir \& Wardani, 2019). Sehingga dengan pemilihan langsung maka masyarakat akan belajar bagaimana menjadi seorang warga negara yang baik yakni warga negara yang kritis, berpartisipasi dan bertanggung jawab. Pemilihan umum mengajarkan masyarakat untuk lebih dewasa dengan cara menerima kekalahan pasangan calon yang diusungnya. Bahkan dalam menentukan pilihan, pemilih benar-benar menganalisis secara cerdas mana tokoh politik yang layak untuk memenangkan kontestasi politik (Lestari, 2018).

\section{SIMPULAN}

Pendidikan Kewarganegaraan memberikan petuah bahwa dalam kontestasi politik harus mengedepankan etika dan norma, tidak melakukan segala macam cara yang inkonstitusional demi menjadi pemenang. Dengan demikian petuah untuk menjadi warga negara yang baik bisa dilakukan ketika para calon kandidat kepala daerah berkompetisi sesuai dengan aturan yang berlaku.

\section{SARAN}

Penelitian ini diharapkan menjadi konsep awal mengenai Pendidikan Kewargaegaraan dalam kehidupan politik. Para akademisi diminta untuk lebih mengkaji lagi petuah Pendidikan Kewarganegaraan sebagai pendidikan politik, hukum, nilai, dan 
lain-lain. Penelitian ini perlu dikembangkan lagi oleh beberapa pakar khususnya yang berkaitan dengan Pendidikan Kewarganegaraan.

\section{DAFTAR PUSTAKA}

Bashori, K. (2018). Pendidikan Politik di Era Disrupsi. Sukma: Jurnal Pendidikan, 2(2), 287-310. https://doi.org/10.32533/02207.2018

Budi Ali. (2012). Politik Identitas Etnis Dalam Kontestasi Politik Lokal. Jurnal Kewarganegaraan, 19(2), 52-60.

Budiman, S. A., \& Setyahadi, M. M. (2019). Peran Ormas Islam Dalam Menjaga Stabilitas Politik Sosial Budaya Indonesia Pasca Pemilu 2019 (Kajian Pustaka Pada Organisasi Islam Terbesar Nu Dan Muhammadiyah). Jurnal Renaissance, 4(2), 560-563.

Bunyamin, M. (2008). Internalisasi Nilai-Nilai Pancasila dan Nasionalisme Melalui Pendidikan Kewarganegaraan. EDUCATIONIST, II(2), 134-144.

Fatwa, A. N. (2016). Pengaruh Kesadaran Politik Terhadap Partisipasi Politik Masyarakat Dalam Pemilihan Bupati Tahun 2013 Didesa Sesulu Kabupaten Penajam Paser Utara. EJournal Ilmu Pemerintahan, 4(4), 1615-1626.

Helen NM. (2019). Dampak Perolehan Pendidikan Kewarganegaraan Terhadap Peningkatan Partisipasi Pemilih Remaja Dalam Pemilihan Umum. Journal of Civic Education, 2(2), 1-14.

Hemafitria. (2015). Pembelajaran PKn Sebagai Pendidikan Politik Pemilih Pemula. Jurnal Edukasi, 13(2), 175-189.

Hermawan, I. C. (2020). Implementasi Pendidikan Politik Pada Partai Politik di Indonesia. JPPHK (Jurnal Pendidikan Politik, Hukum Dan Kewarganegaraan), 10(1), 1-19.

Lestari, E. Y. (2018). Partisipasi Politik Pemilih Pemula pada Pemilihan Walikota Semarang di kota semarang. Jurnal Integralistik, 1(1), 63-72.

Muksin, A. (2018). Partai Politik dan Sistim Demokrasi di Indonesia. Jurnal Sosial Dan Humaniora, 3(6), 777-788. http://journal.unas.ac.id/populis/article/view/476

Nadir, N., \& Wardani, W. Y. (2019). Membangun Pendidikan Politik Dalam Fatsun Demokrasi Pancasila Dan Deliberative. The Journal of Society \& Media, 3(1), 126141. https://doi.org/10.26740/jsm.v3n1.p126-141

Nasution, A. R. (2016). Urgensi Pendidikan Kewarganegaraan sebagai Pendidikan Karakter Bangsa Indonesia melalui Demokrasi, HAM dan Masyarakat Madani. Jupiis: Jurnal Pendidikan Ilmu-Ilmu Sosial, 8(2), 201-212. https://doi.org/10.24114/jupiis.v8i2.5167 
Ngurah, I. G., Edy, I. P., \& Sujana, I. G. (2019). Membangun Kualitas Sistem Politik Demokrasi Indonesia Melalui Pemilu Dalam Perspektif Integrasi Bangsa Dengan Berorientasikan Roh Ideologi Pancasila. Seminar Nasional I Hukum Dan Kewarganegaraan, 74-85.

Nurgiansah, T. H. (2019). Pemutakhiran Kurikulum Pendidikan Kewarganegaraan di Era Revolusi Industri 4.0. Prosiding Seminar Kewarganegaraan Universitas Negeri Medan, 1(1), 95-102.

Nurgiansah, T. H. (2020). Build An Attitude of Nationalism Students At SDN 7 KADIPATEN With The Method of Discusion In The Subject PPKn. Jurnal Serunai Pendidikan Pancasila Dan Kewarganegaraan STKIP Budi Daya Binjai, 9(1), 1-11.

Nurgiansah, T. H., Dewantara, J. A., \& Rachman, F. (2020). The Implementation of Character Education in the Civics Education Syllabus at SMA Negeri 1 Sleman. Jurnal Etika Demokrasi Universitas Muhammadiyah Makasar, 5(2), 110-121.

Nurgiansah, T. H., \& Widyastuti, T. M. (2020). Membangun Kesadaran Hukum Mahasiswa PPKn UPY Dalam Berlalu Lintas. Civic Edu: Jurnal Pendidikan Kewarganegaraan Universitas Pasundan, 2(2), 97-102. https://doi.org/10.1017/CBO9781107415324.004

Rahman, A. (2017). Peran Sekolah Sebagai Sarana Sosialisasi Politik untuk Meningkatkan Partisipasi Politik Pada Pemilih Pemula. Prosiding Konferensi Nasional Kewarganegaraan III, 319-325. http://eprints.uad.ac.id/9800/1/319-325 Asmika Rahman.pdf

Rahman, A. (2018). Konsep Dasar Pendidikan Politik bagi Pemilih Pemula. Pendidikan Ilmu-Ilmu Sosial, 10(1), 44-51.

Sagala, A. I. (2019). Pengaruh Pendidikan Kewarganegaraan Terhadap Partisipasi Pemilih Pemula Pada Pemilihan Umum (Studi Kasus: Pemilu Gubernur Dan Wakil Gubernur Sumatera Utara Tahun 2018) Helen NM Napitupulu. Civic Culture: Jurnal Ilmu Pendidikan PKn Dan Sosial Budaya, 3(1), 185-198.

Sarbaini. (2014). Orientasi Politik Masyarakat Terhadap Pemilihan Partai Politik di Kelurahan Melayu Kecamatan Banjarmasin Tengah. Jurnal Pendidikan Kewarganegaraan, 4(8), 600-607.

Sutisna, A. (2017a). Peningkatan Literasi Politik Pemilih Pemula Melalui Pendekatan Pembelajaran Kontekstual. Prosiding Seminar Nasional Pendidikan FKIP UNTIRTA, $1-14$.

Sutisna, A. (2017b). Strategi peningkatan literasi politik pemilih pemula melalui pendekatan pembelajaran kontekstual. Journal Ilmu Sosial Dan Humaniora, 6(2), $135-146$. 
Sutrisno, S., Yuningsih, N. Y., \& Agustino, L. (2018). Komparasi Teori Marketing Politik $4 \mathrm{p}$ Menurut Niffenegger dan 3p Menurut Adman Nursal. JPPUMA Jurnal Ilmu Pemerintahan Dan Sosial Politik Universitas Medan Area, 6(2), 106-111. https://doi.org/10.31289/jppuma.v6i2.1617

Zulhazmi, A. Z. (2019). Komunikasi Politik Kontestan Pilkada Jawa Tengah 2018. KOMUNIKA: Jurnal Dakwah Dan Komunikasi, 13(2), 153-166. https://doi.org/10.24090/komunika.v13i2.1749 